\title{
Uma Abordagem Histórica das Representações Sociais de Saúde e Doença
}

\section{A Historical Approach to Social Representations of Health and Disease}

\author{
Gil Sevalho'
}

SEVALHO, G. A Historical Approach to Social Representations of Health and Disease. Cad. Saúde Públ., Rio de Janeiro, 9 (3): 349-363, jul/sep, 1993.

This essay presents a historical approach to social representations of health and disease. It follows propositions from the trend of New History, focusing on cultural permanence over long periods of time rather than change. First, the cogency of the model is discussed. Then, a history of representations concerning health and disease is carried out. We perceive that there is a persistence of representations that coexist ambiguous in the indiviudals' minds. Topics like guilt, fear, stressing threats, and decay of the human body have always been part of attitudes regarding disease, in social representations of health and disease.

Key words: Health and Disease; Socioeconomic Factors; History; Social Representations

\section{A APRESENTAÇÃO, UMA DEFESA DE PROPÓSITOS}

Quando apresento uma abordagem histórica das representações de saúde e doença, é necessário que aponte meu ponto de vista. Devo localizar no espaço do conhecimento o lugar de onde parte meu olhar. Desta localização depende o que podemos visualizar.

Inicialmente, quero contar o que li há pouco num artigo de Everardo Duarte Nunes (1992). Trata-se de uma citação de uma autora norte-americana (Fox, 1985) sobre os quarentões como eu, quando, "na plenitude de sua melancolia", não se tornam cinqüientões, mas, sob a ameaça do crescimento desta melancolia na década seguinte, voltam-se para trás e tornamse historiadores. Não sou um historiador de ofício e talvez a constatação anterior justifique a pretensão deste ensaio. Qual seja a de consultar o passado para melhor sentir as inquietações do presente.

Ao trafegar numa ambientação histórica, onde as representações sociais envolvem a saúde e a

\footnotetext{
${ }^{1}$ Departamento de Farmácia Social. Faculdade de Farmácia da Universidade Federal de Minas Gerais. Avenida Olegário Maciel, 2360 - $7^{\circ}$ andar. Belo Horizonte, MG, 30180-112, Brasil.
}

doença, faço-o através de projetos e propostas mais recentes, ligadas a uma conformação determinada da Ciência da História. Refiro-me, então, à ordem simbólica, que é o que dá vida à realidade, pois é onde se movimentam os corpos e as imagens, onde se expressam as ambigüidades humanas, os pensamentos, sensações, ações e atitudes que refletem as representações coletivas. Neste contexto, utilizo alguns conceitos e noções que desejo comentar. Vale dizer ainda que, ao identificar a história como um saber interpretativo da memória coletiva (Birman, 1991) e compor minha exposição com aportes da chamada história nova dos Annales, o recurso ao emprego de noções, enquanto elementos mais imprecisos e mais abertos que os conceitos (Minayo, 1992), é necessário.

Vem da história nova da escola dos Annales, nascida a partir da fundação da revista Annales D'Histoire Économique et Sociale por Lucien Febvre e Marc Bloch em 1929, a perspectiva alternativa da "longa duração" para o tempo histórico. Fernand Braudel, o grande historiador da segunda fase dos Annales das décadas de 1950 e 60, atribuía ao tempo longo uma consistência maior do que ao tempo curto da tradicional história dos acontecimentos. Uma postulação que, posteriormente, opôs também uma história cultural ao fôlego curto de uma história 
política conduzida por revoluções breves. No tempo longuíssimo, onde Braudel visualiza "camadas de história lenta", aparentemente imóveis, movendo-se porém na "semi-imobilidade", é que se abrigam as estruturas, arquiteturas às vezes "de uma vida tão longa que se convertem em elementos estáveis de uma infinidade de gerações: obstruem a história entorpecem-na e, portanto, determinam a sua marcha" (1986).

Penso que não há como transitar numa história das representações de saúde e doença, através da história tradicional que tem o seu fundamento nos acontecimentos, eventos rápidos, enquanto motores da humanidade. Acredito na plurisecularidade das relações entre os seres humanos e os seus corpos, relações que forjam as representações de uma cultura da saúde e da doença, admitindo o caráter provocativo que reveste tal expressão. Eis porque, mais do que mudanças, procuro as permanências culturais na longa duração.

Uma abordagem histórica assim construída, onde as representações e sua alimentação de vestígios imemoriais, traços da consciência e elementos do inconsciente são o centro da atenção, apresenta problemas no que diz respeito ao seu encaixe em uma taxonomia precisa. No âmbito da história nova, a perspectiva que escolhi pode ser situada como uma história das mentalidades, dominante na fase mais recente dos Annales (Hunt, 1992), ou uma história das culturas. Para Ginzburg (1991), “o que tem caracterizado os estudos de história das mentalidades é a insistência nos elementos inertes, obscuros, conscientes de uma determinada visão de mundo".

Ginzburg afirma que o componente racional participaria da história da cultura, mas esclarece, também, que para alguns autores esta última englobaria tanto a história das idéias quanto a das mentalidades. Como persigo as permanências culturais no tempo longo, soam-me bastante interessantes as observações de Vovelle (1990) de que as mentalidades, "campo privilegiado da longa duração", significariam a culminância da história social, um domínio onde "as pertinências se inscrevem em atitudes e representações coletivas". Domínio que Ariès (1990) remete a um "inconsciente coletivo". Para a crescente história das mentalidades, o cultural não é subordinado ou determinado pelas relações políticas e econômicas, mas sim o próprio espaço onde estas se manifestam.

De qualquer modo, neste texto, examino a possibilidade de uma história das representações de saúde e doença, como elementos da ordem cultural, sob uma escala de visualização ampla. Assim procedendo, não desprezo, como pode parecer a princípio, o poder revelador da observação microscópica da microhistória (Levi, 1992) ou a importância do relativismo cultural. No entanto, meu objeto de interesse no momento é a perspectiva geral, até mesmo como fonte de discussão para investigações mais segmentadas.

Devo considerar o que afirma Ginzburg (1991) ao alertar para o grande risco de extrapolações indevidas decorrente da "conotação terminantemente interclassista da história das mentalidades", embora, ao mesmo tempo, não negue a "legitimidade de investigações desse tipo”. Afinal, como percebe Le Goff (1988), é na história das mentalidades, uma história em construção, que se acha "o que Cézar $e$ o último soldado de suas legiões, São Luís e o camponês de seus domínios, Cristóvão Colombo $e$ o marinheiro de suas caravelas têm em comum".

Sem dúvida, este aspecto interclassista é hoje uma questão central do debate travado entre historiadores de linha marxista e historiadores das mentalidades, quando ambos os grupos assumem a predominância da cultura na formulação histórica (Vovelle, 1991; Hunt, 1992).

No entender de Herzlich (1991), ao tratar das representações de saúde e doença,

"por ser um evento que modifica, às vezes irremediavelmente, nossa vida individual, nossa inserção social e, portanto, o equilíbrio coletivo, a doença engendra sempre uma necessidade de discurso, a necessidade de uma interpretação complexa e contínua da sociedade inteira."

A autora sustenta que "o estudo das variações segundo grupos sociais ou segundo populações particulares pode, certamente, constituir um aporte", embora tal perspectiva não lhe pareça fundamental. Para ela o recurso à história como um caminho para a análise das concepções da doença deve perseguir o conjunto dos fenôme- 
nos macrossociais, a demarcação da articulação das representações de saúde e doença com a patologia de uma época e sua configuração histórica e ideológica (Herzlich, 1991).

Outra característica de minha abordagem, que deve ser considerada, é o fato de que não componho, como seria coerente com as propostas da história nova, uma "história vista de baixo" (Burke, 1992; Sharpe, 1992), contada a partir da visão das pessoas comuns, da visão do paciente no caso (Porter, 1985). Muitas das informações que utilizo, como algumas constantes da obra de Tamayo (1988) que se refere aos conceitos e às noções sobre saúde e doença, são pertinentes ao pensamento médico. No entanto, não percorro uma história institucional pontuada pela apologia dos feitos dos grandes vultos da medicina, típica da história tradicional. Busco as representações coletivas em uma história vaga, borrada, forjada da lentidão dos espíritos, das mentalidades, visões de mundo.

$\mathrm{Na}$ discussão deste ponto na história das representações que proponho, a opinião de Herzlich, mais uma vez, me é interessante. A autora (Herzlich, 1991) afirma que lhe parece que

"É impossível reduzir o funcionamento das representações ao princípio objetivo da distância que separa leigos e médicos, detentores do saber dominante. [...] a doença está hoje nas mãos da medicina, mas ela permanece sendo um fenômeno que a ultrapassa. [...] Em um plano mais geral, a história da medicina nos mostra de que modo as relações entre saber médico e concepções do senso comum podem estabelecer-se nos dois sentidos, sem uma dependência em sentido único, mas com vaivéns entre o pensamento erudito e o pensamento de senso comum."

Sobre o mesmo aspecto, outra perspectiva que deve ser apontada com atenção é a de Ginzburg (1991), quando faz suas colocações acerca de Bakhtin (1993) e uma "circularidade", uma reciprocidade de influências entre culturas subalterna e hegemônica. Ao estudar a visão de mundo do moleiro Menocchio, no século XVI, o autor (Ginzburg, 1991) admite esta relação dialética entre cultura popular e cultura de elite, quando anuncia a necessidade da superação de "uma concepção antiquada de folclore", sustentada por aqueles que distinguem "nas idéias, crenças, visões de mundo das classes subalternas nada mais do que um acúmulo desorgânico de fragmentos das idéias, crenças, visões de mundo elaboradas pelas classes dominantes vários séculos antes."

Ginzburg (1991) situa a segunda metade do século XVI, como o período a partir do qual cada vez mais as classes dominantes e, conseqüentemente, a cultura das elites se afastaram das classes populares e de sua cultura, o que teria levado à desintegração gradual desta circularidade. Especificamente quanto à questão da saúde e da doença, o moderno atestado de cientificidade da medicina, oportunizado a partir do século XIX com o nascimento da clínica (Foucault, 1977), estabeleceu, com a abertura dos corpos, a hegemonia do discurso médico sobre a doença, caracterizando a percepção do paciente, enquanto "sujeito-da-doença” (Herzog, 1991). O domínio sobre os corpos poderá ter significado também o domínio da cultura erudita, médica, sobre as representações de saúde e doença. Vale dizer que é o espaço imaginário destas representações, onde se inscrevem as relações entre os seres humanos e os seus corpos ou entre os corpos dos seres humanos no coletivo, a matéria de uma nova história cultural do corpo (Revel \& Peter, 1988; Laqueur, 1992; Porter, 1992).

Não creio, contudo, no modelamento absoluto da memória coletiva pela cultura médica, mesmo quando diante da doença se utilizam as tecnologias modernas, como é o que pretende Boltanski (1989). Esta, aliás, foi minha preocupação central ao especular sobre as permanências culturais no uso do medicamento alopático moderno (Sevalho, 1992). Embora os historiadores da história nova sejam por excelência medievalistas, como é o caso dos da escola dos Annales e de outros como o citado Ginsburg, creio que muitas de suas postulações transcendam tal amplitude de época. Penso que nas representações de saúde e doença persiste uma certa dinâmica de influências recíprocas da órbita cultural. Assim, neste ensaio que chega até a ambientação da microbiologia do início do século XX, insisto na investigação de permanências culturais na longa duração do tempo como participantes nas expressões das represen- 
tações sociais de saúde e doença. No âmbito do espaço do conhecimento do coletivo, onde se interpenetram a história, a antropologia e a psicologia, onde habitam e se relacionam as falas, os movimentos dos corpos e as atitudes. Onde persistem os automatismos e os reflexos, "velharias intelectuais" (Le Goff, 1988), elementos contraditórios combinados, vestígios encravados no tempo, semi-soterrados nos sítios da memória, que constituem, no entender de Vovelle (1991), "o que há de mais precioso" na história.

\section{UMA HISTÓRIA DAS REPRESENTAÇÕES DE SAÚDE E DOENÇA}

A história das representações de saúde e doença foi sempre pautada pela inter-relação entre os corpos dos seres humanos e as coisas e os demais seres que os cercam. Elementos naturais e sobrenaturais habitam estas representações desde tempos imemoriais, provocando os sentidos e impregnando a cultura e os espíritos, os valores e as crenças dos povos. Sentimentos de culpa, medos, superstições, mistérios, envolvendo o fogo, o ar, a terra, os astros, a organização da natureza, estão indissoluvelmente ligados às expressões da doença, à ocorrência de epidemias, à dor, ao sofrimento, às impressões de desgaste físico e mental, à visão da deterioração dos corpos e à perspectiva da morte. Le Goff (1991b) aponta que

"A doença pertence não só à história superficial dos progressos científicos e tecnológicos como também à história profunda dos saberes e das práticas ligadas às estruturas sociais, às instituições, às representações, às mentalidades".

As representações primevas de saúde e doença foram mágicas. Entre os povos sem escrita, a doença era vista como o resultado de influências de entidades sobrenaturais, externas, contra as quais a vítima comum, o ser humano não iniciado, pouco ou nada podia fazer.

Também no contexto das representações mágicas, os antigos povos da Mesopotâmia sumérios, assírios, babilônios — "haviam postulado uma sociedade sobrenatural de 'deuses' concebidos à sua imagem colocada no superlativo" (Bottéro, 1991). Estes povos forjaram "uma série de personalidades inferiores (...) aos criadores e soberanos do universo, mas superiores às suas vítimas", os demônios que se apossavam dos corpos, provocavam as doenças e deviam ser exorcizados.

Em uma concepção seguinte, a doença participava das crenças religiosas, era obra dos deuses. Inicialmente era fruto do humor divino, independente do comportamento humano. Faz parte, esta visão, das "interpretações religiosas da doença como conseqüência da fatalidade (...) a doença-maldição" (Laplantine, 1991). Outra representação também religiosa, mais elaborada porquanto relacional, é a de "uma conseqüência necessária provocada pelo indivíduo ou pelo grupo (...) é a doença-punição" (Laplantine, 1991).

Certos aspectos de caráter religioso, maldições ou castigos divinos, ainda hoje revestem as representações de saúde e doença. $\mathrm{O}$ medo e a culpabilidade sempre participaram da relação do ser humano com a doença, conformando permanências culturais. Estes aspectos resistem entre crenças ainda existentes que cultuam a pureza como uma ligação rigorosa e permanente ao primitivo e um isolamento dos costumes atuais, ou mesclados na cultura geral de nosso tempo. A sífilis, com seu caráter venéreo, na primeira metade do século XX, e a presente epidemia de AIDS, inicialmente entre homossexuais masculinos e usuários de drogas endovenosas, trouxeram à tona uma série de preconceitos morais.

Hoje, em todo o mundo, os xamãs continuam exercendo sua função, realizando curas através de rituais, expulsando coisas e espíritos que invadem os corpos das vítimas e os sacerdotes ainda exorcizam os demônios. Muito a propósito, portanto, vêm as observações de Gonçalves (1990), quando chama a atenção para o fato de que as expressões manifestações clínicas e entidades mórbidas, de inspiração notadamente sobrenatural, integram o jargão médico moderno, referindo-se aos sintomas e doenças.

Os egípcios que habitaram o vale do rio Nilo há cerca de 5.000 anos desenvolveram uma certa naturalização da saúde e da doença, junto às suas crenças sobrenaturais, mágicas e religiosas. Admitiam a existência de um princípio, o whdw, que aderido à matéria fecal poderia 
chegar ao sangue, coagulando-o e levando ao apodrecimento do corpo, provocando o aparecimento de supurações e abcessos. Segundo Tamayo (1988), a noção do whdw pode ter se originado de interpretações religiosas associadas à mumificação, à conservação dos corpos. Os egípcios acreditavam que o whdw, a partir do intestino, causava a putrefação dos corpos e o mau cheiro. Na velhice, haveria uma absorção cada vez maior do whdw.

Esta naturalização da saúde e da doença foi passada aos gregos, através do Mar Mediterrâneo. Embora no Oriente chineses e hindus já relacionassem elementos da natureza e do corpo humano, foram Hipócrates e seus seguidores, com sua perspectiva humoral, que estabeleceram de modo mais evidente no Ocidente uma passagem do sobrenatural para o natural no que diz respeito às representações de saúde e doença.

As concepções dos gregos quanto às enfermidades foram anteriormente mágicas e religiosas, onde atuavam os templos e sacerdotes do deus da medicina, Asclépio, pai de Hygieia, deusa da saúde, e Panakeia, que dominava as artes dos remédios das plantas e da terra. O termo pharmakon do grego arcaico significava sacrifícios feitos aos deuses em busca de curas. Já no âmago da escola hipocrática do século V a.C., está, no dizer de Capra (1988), "a convicção de que as doenças não são causadas por demônios ou forças sobrenaturais, mas por fenômenos naturais..."

A interpretação da saúde e da enfermidade pela concepção humoral está apoiada em dois postulados básicos (Tamayo, 1988). O corpo humano é formado por um número variável de líquidos, e a saúde é o equilíbrio entre os humores, enquanto a doença é o desequilíbrio, o predomínio de algum dos humores sobre os demais. Mossé (1991) percebe que

"do mesmo modo que o desequilíbrio entre os vários elementos que constituem a cidade (grega: acréscimo meu) é fonte de perturbação e só pode ser ultrapassado pela igualdade perante a lei (isonomia), também a cura do corpo está ligada a um regresso ao equilíbrio”.

Os gregos hipocráticos, como os chineses e hindus em outros contextos e com complexida- des diversas, acreditavam em certos sistemas de correspondência entre elementos do corpo e elementos fundamentais da natureza. Para os gregos, quatro humores corporais correspondiam à água, à terra, ao fogo e ao ar, sendo o equilíbrio do sistema a condição para a saúde. Equilíbrio que devia ser perseguido, através dos cuidados com o corpo, hábitos alimentares e exercícios físicos, em uma convivência harmônica com o ambiente natural, onde o ser humano era visto como parte integrada desta natureza.

A concepção humoral dos gregos, inclusive a higiene para a conservação da saúde dos corpos e das mentes, foi continuada por Galeno, médico grego que passou grande parte de sua vida na Roma antiga, no século II. Sigerist (1987) informa que, então, as termas romanas não eram apenas casas de banho, possuindo ginásios para a prática de esportes, salas de leitura e bibliotecas. Muito antes de Galeno, entre os séculos VI e IV a.C., os romanos já haviam desenvolvido um esboço de administração sanitária com leis sobre inspeção de alimentos e construído aquedutos baseados na força da gravidade e esgotos. Desde tempos imemoriais, as perspectivas da infecção, do impuro que ameaça se introduzir nos corpos, através dos alimentos e dos ares corrompidos pelas putrefações, revestiram as representações de saúde e doença. Os egípcios admitiam um princípio infeccioso aderido às fezes, os romanos drenavam os pântanos e os gregos zelavam pelos corpos e acendiam fogueiras para purificar o ar.

Galeno era um escritor prolixo e sua obra literária individual é, talvez, a maior da antigüidade, tendo o seu conteúdo representado dogmas durante cerca de 14 séculos, conformando o que Boorstin (1989) chamou de "a tirania de Galeno". Até mesmo suas observações anatômicas feitas em animais, em virtude da dificuldade para a conservação dos cadáveres e das proibições religiosas, quanto à abertura e à dissecação dos corpos humanos, permaneceram intocáveis por muito tempo. Os escritos de Galeno e o corpus hipocraticum foram depois transmitidos aos médicos árabes que os traduziram e os seguiram na Idade Média, protegendo-os assim do catolicismo romano e da Santa Inquisição.

Na Idade Média, o mundo ocidental viveu um período profundamente influenciado pela Igreja 
Católica, onde as representações de saúde e doença retomaram um caráter fundamentalmente religioso. Até o século XII, quando tiveram início os diversos renascimentos dos conhecimentos pagãos, os árabes, no mundo islâmico, seguiam os ensinamentos de Hipócrates e Galeno, enquanto a religiosidade dominava a cultura e os espíritos no mundo cristão. Os hospitais do Ocidente cristão, por exemplo, não eram recursos terapêuticos como os do final do século XVIII, onde Foucault (1977) percebeu o nascimento da clínica moderna. Eram casas de assistência aos pobres, abrigos de viajantes e peregrinos, mas também instrumentos de separação e exclusão quando serviam para isolar os doentes do restante da população. Um dos valores básicos que envolvia a existência dos hospitais do medievo era a caridade, pois cuidar dos doentes ou contribuir financeiramente para a manutenção destas casas significava a salvação das almas dos benfeitores. As ordens cavaleiras de cruzados como a de São João ou dos hospitaleiros fundaram hospitais em suas rotas (Rosen, 1980). Enquanto representação terapêutica, estes hospitais são a analogia social das sangrias individuais que lhes foram contemporâneas, expulsando o mau e purificando o corpo social.

Antes de Descartes, como lembra Porter (1992), a religiosidade cristã da época já separava corpo e mente, enquanto carne e espírito. Embora o zelo para com os corpos não fosse tão importante, quanto aquele para com os espíritos, permanecia uma certa necessidade de manter puro o corpo. Se para os gregos antigos a naturalização das representações compreendia uma higiene dos corpos, para os cristãos do Ocidente Medieval os corpos eram os receptáculos das almas (Sigerist, 1987).

Durante a peste negra ou morte negra do século XIV, uma epidemia que pode ter aniquilado dois terços da população européia de então, cortejos de fiéis se auto-flagelavam pelas cidades, expiando seus pecados. Giovanni Bocaccio escreveu então o seu "Decameron", onde conta uma centena de histórias, através de personagens entregues ao amor e ao prazer numa vivenda nos arredores de Florença, onde tentavam escapar das devastações da peste. Em 1347, em Veneza, e em 1377, em Ragusa, inspirada em passagens bíblicas onde era des- crito o ostracismo dos leprosos, surgiu a quarentena. Embora a primeira teoria do contágio seja atribuída a Girolamo Fracastoro em meados dos 1500, Botéro (1991) cita uma carta de um rei babilônio de 1780 a.C., alertando sua esposa sobre a possibilidade do contágio de uma certa "chaga purulenta". Nos anos 1300, ao tempo da peste negra, um médico árabe relatava que a doença podia ser contraída pelo contato com os doentes ou através de peças de vestuário, louça ou brincos (Sournia \& Ruffie, 1986). De qualquer modo, na visão de mundo dos cristãos medievais, estava contextualizado o temor que a doença imprimia. A sensação de que devia ser mantida à distância, o necessário afastamento do perigo desconhecido pressentido, o medo do sofrimento e da morte. Ao comentar a epidemia de peste da época e dissertar sobre uma "história do medo no Ocidente", Delumeau (1989) afirma que

"É bem verdade que era preciso, se possível, fugir ou, na falta disso, isolar e isolar-se (...) o bom senso popular tinha portanto razão a esse respeito contra os eruditos que se recusavam a crer no contágio".

Nos séculos XII, XIII e XIV, danças macabras eram promovidas nos cemitérios, pinturas e poesias mencionavam incessantemente a morte, a putrefação e o mau cheiro dos cadáveres. Imagens de ventres rasgados devorados por vermes eram citações artísticas constantes. No dizer de Huizinga (1978), "em nenhuma outra época como no declínio da Idade Média se atribuiu tanto valor ao pensamento da morte". Se o catolicismo medieval anunciava a cura para todos os males pela religião, igualando as pessoas perante Deus, também a morte, no final da Idade Média, as igualava enquanto a obrigatória privação final de todos.

O declínio da Idade Média resultou da sedimentação gradual de uma série de aspectos culturais no mundo ocidental. Desde o século XII até o século XVII, em vários momentos e em vários pontos a partir da Itália, o conhecimento pagão renasceu. Uma racionalidade humanista de cunho profundamente individualista foi se impondo sobre o anonimato e o cerceamento da crítica e da criatividade que o catolicismo havia imposto. O capital mercantil 
afirmou-se sobre as relações sociais feudais, com o predomínio de uma burguesia mercantil e bancária sobre as tradições de sangue e o mando do patrimônio da terra dos senhores feudais, nobres de linhagem (Luz, 1988). O mercantilismo surgiu com o ser humano livre oriundo dos burgos medievais, onde circulavam mercadorias e idéias. A marcação do tempo, antes pontuada pela chamada dos sinos para as obrigações religiosas, passou ao domínio dos relógios e dos compromissos do comércio, ainda que os negócios se realizassem sempre sob a invocação divina (Le Goff, 1991a). As artes e as ciências floresceram. As línguas nacionais pouco a pouco substituíram o latim. Os Estados nacionais se constituíram.

Desde o século XII, "o século das universidades" (Le Goff, 1989), as obras hipocráticas e de Galeno, reintroduzidas no Ocidente pelos árabes, foram traduzidas do grego e do árabe para o latim e para os idiomas nacionais. Como sustenta Le Goff (1989), os produtos de valor vinham do Oriente e "junto com as especiarias $e$ as sedas, os manuscritos trazem a cultura greco-árabe para o Ocidente cristão". Com o pretexto inicial de dos ímpios tudo retirar para melhor conhecê-los e combatê-los, os conhecimentos dos árabes foram repassados aos cristãos.

Um outro contexto científico foi se estabelecendo, conformando uma cisão entre o ser humano e a natureza. $\mathrm{O}$ individualismo, a criatividade, a laicização do saber forjaram a ambientação cultural de onde emergiu o racionalismo científico, base da ciência moderna, modelado no empirismo indutivo e no racionalismo dedutivo mecanicista de Francis Bacon e de René Descartes. O ser humano que acompanhava o nascimento da ciência moderna era conquistador e proprietário da natureza, não mais seu partícipe e observador harmonioso. Uma perspectiva de domínio sobre o mar, a terra e os elementos inspirou e movimentou as navegações e os descobrimentos, as ciências e as artes, mas também isolou o ser humano, renegando-o a uma histórica solidão, enquanto patrocinador de um desenvolvimento tecnológico profundamente antiecológico. Esta perspectiva abriu caminho para as práticas terapêuticas intervencionistas, ao escantear a tolerância e o reforço das reações naturais, a vis medicatrix naturae, preconizada pelos gregos antigos.

Neste tempo de efervescência cultural, as nações e os conceitos sobre saúde e doença proliferaram. No entanto, ao nível das mentalidades na longa duração, as permanências são mais evidentes do que as pretensas mudanças.

O desenvolvimento da astrologia inspirou a combinação dos velhos saberes da Mesopotâmia e do Egito com as teorias de Galeno. Nos diagramas do homem zodiacal as partes do corpo humano foram relacionadas aos astros e signos, indicando as melhores e piores épocas para o uso de certos remédios (Boorstin, 1989). As influências astrais estavam ligadas à ocorrência de epidemias e participaram das "constituições" de Thomas Sydenham no século XVII e de sua classificação das doenças, segundo as espécies botânicas. Constituições que Gonçalves (1990) define como "agrupamentos singulares de uma espécie mórbida vinculados a conjunção única de um certo número de influências ambientais (...)." (Grifos meus). As participações astrais deram um sentido cósmico às epidemias até o século XVIII, quando as influências passaram a designar especificamente as nossas gripes de hoje.

É interessante notar a riqueza das representações registrada nos documentos relativos à constituição pestilencial de Pernambuco, no final do século XVII. O que pode ser visto nas descrições da epidemia de febre amarela, contidas nos escritos do médico português Ferreira da Rosa, publicados em 1694, e nos "Bandos de Saúde", proclamações contendo normas para controle da pestilência mandadas executar pelo governador da província, o Marquês de Montebelo. Segundo estas fontes, investigadas por Machado et al. (1978) e Santos-Filho (1977), na ocorrência estaria comprometido o ar corrompido pela "qualidade contagiosa dos astros", por vapores das águas "imóveis e fechadas", de corpos e alimentos podres, bem como a "ira de Deus", ofendido pelos "nossos pecados". Assim, das medidas pregadas para enfrentar a doença constavam o controle do porto, o isolamento dos doentes, a caiação e a borrifação das casas com perfumes e vinagre, a limpeza das ruas, a feitura de fogueiras com ervas cheirosas, o controle da prostituição e da moral, a realiza- 
ção de missas, orações e procissões, a aplicação de sangrias e a administração de purgantes aos doentes e a lavagem "por quarenta dias" de suas vestimentas e roupas de cama.

Entre as concepções dos iatroquímicos, iatromecânicos e animistas dos séculos XVII e XVIII, os limites eram imprecisos, nelas misturando-se invocações divinas e espirituais com chamamentos à química e à física. Representações de ordem ontológica, que vêem a doença como um ser externo que invade os corpos, se imbricavam com circulações humorais, reações químicas, fermentações, movimentos corpusculares e forças da ordem física.

A iatroquímica teve sua origem no século XVI nas proposições alquímicas de Philipus Theophrastus Aureolus von Hohenheim, o Paracelso, que acreditava que a vida era um processo químico e que a doença era um desequilíbrio na química do corpo. Ao lado de suas crenças em bruxarias e demônios, Paracelso percebeu uma química da vida nos corpos humanos muito antes de Lavoisier confirmá-la com a demonstração de que a respiração era uma forma de oxidação, na fundação da química pneumática, nos anos 1700. Em sua continuidade, a iatroquímica postulou a existência de um gás espiritual, contido nos alimentos. $\mathrm{O}$ corpo não teria a possibilidade de, através de um processo de fermentação, absorver quimicamente os alimentos em decorrência do pecado original, provocando a formação de resíduos que se combinavam com elementos imateriais e humores dos seres humanos, originando as doenças (Tamayo, 1988). Os iatromecânicos seguiam as analogias com as máquinas do mecanicismo cartesiano, que comparava o corpo humano a um relógio e a doença ao seu mau funcionamento mecânico. Da segmentação do corpo em peças e sistemas mecânicos surgiram os aparelhos e sistemas orgânicos que abrigaram as especialidades médicas modernas. $\mathrm{Na}$ perspectiva dos iatromecânicos os sólidos orgânicos funcionariam impulsionados por forças, ao nível da estática, e os líquidos, humores, seguiriam as leis da hidráulica (Tamayo, 1988), que foi como William Harvey descreveu a circulação do sangue em 1628 , utilizando imagens de bombas, válvulas e canais. Os sólidos e líquidos do corpo movimentavamse, combinando reações químicas com noções da teoria corpuscular da física de Isaac Newton em sua visão da grande máquina do mundo criada por Deus. Para os animistas ou vitalistas, o ânima, a alma enquanto princípio vital, habitava o corpo humano e era responsável pelo tônus que mantinha sua vida, sua conservação e auto-regulação. O corpo sem a alma se deterioraria. $O$ tônus propiciado pelo ânima se distribuiria pelo corpo, através do sangue e com o seu desequilíbrio, que resultaria em contrações ou relaxamentos, a doença ocorreria.

Com uma leitura do corpo humano, onde a atenção central não era colocada mais nos humores, líquidos, os elementos sólidos passaram a participar mais das representações de saúde e doença, alvos de forças físicas, donos de movimentos que dão forma e expressão à vida. A imagem de fibras sólidas que se distendiam e se contraíam foi a base da irritabilidade de Francis Glisson e Albrecht von Haller e da excitabilidade de John Brown, nos séculos XVII e XVIII. O excesso ou a falta de estimulação de fatores externos ao corpo possibilitaria a doença, o que já admitia, então, uma consideração de limites mensuráveis entre o normal e o anormal ou patológico.

Canguilhem (1990) e Foucault (1977) apontam que estímulos externos, favorecendo contrações e distensões de fibras, debilitando nervos e cérebros, como nas febres do solidismo de William Cullen, e movimentando tecidos constituíram o suporte conceitual sobre o qual se assentou a medicina fisiológica de François Joseph Victor Broussais. Para Broussais, a doença não era algo que se instalava no corpo, mas o próprio movimento dos tecidos devido aos estímulos irritantes. Broussais combatia, no encontro dos séculos XVIII e XIX, a clínica nascente de Pierre-Jean-Georges Cabanis, Phillipe Pinel e Marie François Xavier Bichat, e as classificações formuladas por seus estudos de casos à beira dos leitos dos hospitais, devidamente transformados em instrumentos terapêuticos e educacionais como parte dos benefícios sociais da Revolução Francesa. A medicina fisiológica de Broussais entendia que as doenças não podiam ser consideradas como seres particulares com identidades estabelecidas pela nosografia de Pinel, uma localização de sinais e sintomas combinados. Acreditava que as inflamações que conduziam às febres eram 
tratadas pelos clínicos em uma concepção ontológica.

Enquanto a clínica moderna se desenvolveu nos hospitais e nos laboratórios, onde mais tarde se abrigaram a fisiologia experimental de Claude Bernard e a microbiologia de Louis Pasteur e Robert Koch, as idéias de Broussais inspiraram a medicina social que surgiu com o avanço da revolução industrial no século XIX.

Os Estados nacionais que haviam emergido do declínio da Idade Média se desenvolveram no contexto das monarquias absolutistas e do mercantilismo. Estas nações constituíram sua riqueza, através da quantidade de metais preciosos acumulada, tendo, assim, que alimentar uma produção cada vez maior e colonizar novos territórios. Como consequiência, a necessidade de conhecer suas populações, contá-las, era imperativa, sendo esta contagem condição para verificação da grandeza nacional, que dependia, então, da quantidade de riqueza circulante e do tamanho dos exércitos, o poder bélico. " $O$ povo como elemento produtivo, o exército como elemento beligerante precisam não apenas do número, mas também da disciplina e da saúde" (Almeida-Filho, 1989). Contar o povo significava, também, contar os mortos e saber a razão destas mortes. Contudo, como acentua Gonçalves (1990), "só é possível contar após haver qualificado o evento de uma certa forma". Certamente este foi um dos impulsos que movimentaram os classificadores de doenças dos séculos XVII e XVIII, de Thomas Sydenham a François Boissier de La Croix des Savages e Phillipe Pinel. Um esforço ao qual se integrou, também, o naturalista e classificador Carl von Lineu.

Entre os primeiros classificadores a inspiração foi a botânica. Os sintomas foram agrupados e catalogados, segundo classes, ordens, gêneros e espécies. Esta forma de representação social de saúde e doença assimilava certas características como os períodos do ano de maior ocorrência das doenças, já que estas periodicidades eram observadas nas plantas e nos pássaros (Tamayo, 1988). À semelhança das plantas, em uma concepção ontológica, as doenças nasciam, cresciam e morriam, possuindo também uma história natural.

Deve ser considerado que a nosografia de Pinel tendia para uma descrição de sintomas e sinais ambientada na clínica, que postulou uma semiologia que tinha a atenção centrada na doença, que se apropriava do doente, seu "objeto transitório" (Foucault, 1977). Uma semiologia guiada pelos sentidos, contextualizada no sensualismo do filósofo empirista do século XVIII Etienne Bonnot de Condillac, onde a palpação, a percussão e a ausculta arrancavam do corpo os segredos que a doença, o mal, ocultava do próprio doente. Assim, enquanto a nosologia de Des Sauvages agrupava a hemoptise entre as hemorragias e a tísica entre as febres, Pinel relacionava a dispnéia, comum na asma e nas doenças do coração, com outras desordens em função da identificação de uma patologia.

No entender de Foucault (1979), o esforço ordenador e classificador de inspiração botânica da medicina das espécies envolveu uma ação terapêutica sobre o meio ambiente, do qual brotava a doença. Este projeto de ampliação da intervenção médica, uma penetração do conhecimento médico no domínio do ambiente social, aplicado ao panorama mercantilista da Alemanha e da França do século XVIII e ao capitalismo incipiente da Inglaterra industrial do século XIX, fez nascer a medicina social no entrelaçamento de três movimentos apontados por Foucault (1979). A polícia médica alemã, uma medicina de Estado que instituiu medidas compulsórias de controle de doenças, a medicina urbana francesa, saneadora das cidades enquanto estruturas espaciais que buscavam uma nova identidade social, e, por último, uma medicina da força de trabalho na Inglaterra industrial, onde havia sido mais rápido o desenvolvimento de um proletariado. Destes movimentos surgiu a medicina social, impulsionada pelos revolucionários de 1848 e suas perspectivas de reformas econômicas e políticas, como uma empresa de intervenção sobre as condições de vida, sobre o meio socialmente organizado pelo modo de vida capitalista conformado pela Revolução Industrial.

Como descreve Hobsbawm (1979), o século da instalação definitiva da Revolução Industrial foi um tempo de superlativos, onde proliferavam os estudos estatísticos, atestados quantitativos do sucesso capitalista, e as teorias científicas evolucionistas, surgidas da "descoberta da história como um processo de evolução lógica". 
Exemplares desta forma de pensar as coisas foram o positivismo de Augusto Comte, que influenciaria todo o conhecimento científico do século XX, a evolução das espécies de Charles Darwin, que estendeu as idéias da teoria populacional de Thomas Robert Malthus dos seres humanos para os animais, e a economia política de Karl Marx.

No entanto, algo não aparecia nas estatísticas. Os graves problemas sociais do início do capitalismo industrial, as desastrosas condições de vida e trabalho, geradas pela formação e crescimento dos núcleos urbanos e pela necessidade cada vez maior de expandir o capital industrial, às custas da exploração da força de trabalho e da pobreza. Mendigos, marginais, artesãos e proletários urbanos iniciais amontoavam-se na miséria e na imundície, e ainda que sua consciência política não fosse única, o seu ódio aos ricos e sua revolta contra as condições em que viviam, aliados ao despertar que a experiência da revolução francesa havia lhes proporcionado, foram as forças motivadoras dos movimentos libertários de 1848, que se espalharam por toda a Europa Ocidental e Central. E foi nesta revolução européia, na assimilação de suas proposições por uma intelectualidade burguesa, que surgiram os preceitos de uma medicina social, controladora do meio ambiente prejudicial, terapeuta das condições de vida. Uma medicina que se auto-reconhecia como seguidora da medicina fisiológica de Broussais e adversária da clínica, que entendia como um projeto ontológico que perseguia somente os sinais e sintomas da doença e não as suas causas, que a medicina social admitia como sendo os miasmas, gases pútridos emanados da corrupção de matérias diversas, expelidos na deterioração crítica das condições de vida (Virchow, 1962).

A medicina de Broussais via a saúde e a doença limitadas entre si pelo excesso ou diminuição do trabalho fisiológico normal sob a ação de estímulos ambientais externos, entre estes os miasmas. Mas é na introdução da categoria energia nas concepções de ambas as medicinas que Garcia (1989) percebe um interessante ponto comum entre a medicina fisiológica e a medicina social. Energia considerada enquanto categoria oriunda da termodinâmica da física de Newton, que, no dizer de Capra (1988), “desenvolveu uma completa formulação matemática da concepção mecanicista da natureza", reunindo o empirismo indutivo de Bacon ao racionalismo dedutivo de Descartes. Para Garcia (1989),

"conceber a doença como uma variação quantitativa (...) de uma norma supõe um homem que possa separar uma parte de si mesmo, um potencial, para que seja utilizada por outra pessoa, para logo voltar a produzir esta mesma energia, ou seja, supõe o operário em um sistema capitalista".

Assim, esta energia referida deve ser vista como força potencial: a força de trabalho sobre a qual se debruçava a medicina social e o tônus normal que por excitação, irritação, podia ter seus níveis fisiológicos normais alterados na medicina fisiológica, estando a perspectiva da doença ligada ao desgaste físico, à deterioração dos corpos, presente em ambas as situações. Penso que, certamente, esta maneira de representar a saúde e a doença propiciou a introdução futura da idéia do estresse. Como aponta Castiel (1993), as noções relativas ao estresse se originaram de uma leitura física da distensão e da possível deformação, perda presumível da integridade dos sólidos orgânicos do corpo submetidos a tensões. Não há, pois, como não admitir que as capacidades física e mental normais possam ser perdidas, quando esforços, trabalhos, irritações, excitações levam ao cansaço, à exaustão, ao desgaste do corpo humano, ao estresse.

Apesar da formulação de uma teoria dos miasmas ser geralmente atribuída a Giovanni Maria Lancisi, nos séculos XVII e XVIII, com o seu estudo sobre a malária, como um conjunto de febres dos pântanos, os maus ares já eram temidos há muito. Estavam presentes nas representações de saúde e doença dos egípcios antigos, das obras de saneamento e urbanização da Roma antiga, dos "ares, águas e lugares" dos gregos hipocráticos e de suas fogueiras purificadoras, do medo que dominou os medievais, durante a peste negra, de Fracastoro e suas idéias sobre o contágio, dos escritos precursores de Paracelso sobre as doenças dos mineiros, das doenças ocupacionais de Bernardino Ramazzini em 1700, da medicina das espécies e da própria clínica, contra a qual se debatiam 
os médicos sociais. Corbin (1987) confirma Bichat, um dos mentores da clínica moderna, comparando o odor dos seus flatos ao dos anfiteatros de dissecação de cadáveres que freqüentava e constatando o poder funesto $\mathrm{e}$ impregnante dos miasmas.

Numa história em que as doenças transmissíveis eram as únicas, enquanto expressões de massa, os miasmas estiveram quase sempre associados ao contágio. Mesmo em 1840, na época do embate entre os médicos sociais, anticontagionistas adversários da quarentena, e os contagionistas, que tiveram a afirmação de suas concepções na microbiologia de Pasteur e Koch, algumas doenças "miasmático-contagiosas" eram reconhecidas por Jacob Henle (Tamayo, 1988). No entanto, Henle, o criador dos postulados que mais tarde deram sustentação ao projeto biologicista da microbiologia com Koch, não foi, então, devidamente considerado. $\mathrm{O}$ que se assistiu até o final do século XIX foi a contraposição entre a exclusividade do contagium vivum e a perspectiva dos miasmas.

Desde o sensualismo de John Locke e, posteriormente, de Condillac e do reinado dos sentidos por eles estabelecido, o exercício do olfato passou a pesquisar cientificamente os focos morbíficos nos séculos XVIII e XIX. Mesmo porque há muito existia a crença de que o nariz, por sua proximidade do cérebro, seria o condutor do mais nobre dos sentidos (Corbin, 1987).

Os miasmas eram telúricos, emanados das fendas e dos pântanos, embora de qualquer modo, tenham sempre permanecido ligados aos excrementos humanos depositados na terra e à putrefação. É assim que depois os amontoamentos e os confinamentos humanos se tornaram importantes focos e as ações terapêuticas, desodorizantes, se voltaram contra os cemitérios, prisões, hospitais, navios. Foucault (1979) conta que, no século XVIII, o "Cemitério dos Inocentes", alvo da terapêutica em Paris, era tão superlotado que os cadáveres transbordavam por sobre seus muros. $\mathrm{O}$ já mencionado advento do hospital como recurso terapêutico partiu do esforço organizador e libertador dos ares viciados de Jacques René Tenon que, às vésperas da Revolução Francesa, pensou a separação dos doentes em leitos individuais e a aeração do ambiente interno. E o escorbuto era emblemático, enquanto doença comprovadamente miasmá- tica, pois era contraído na promiscuidade dos navios (Corbin, 1987).

Orientada pela percepção olfativa, a estratégia saneadora e terapêutica caminhou, pouco a pouco, para além dos amontoamentos até o ambiente familiar e a conseqüente desodorização individual, primeiro do outro e depois do próprio dono do sentido olfativo. Uma estratégia que encontrou artefatos exemplares no quarto e na cama de dormir individuais e nos perfumes do século XVIII, já que a necessidade de um contínuo asseio corporal ainda era fruto de discussão. Artefatos, como tais, inacessíveis aos pobres.

Enquanto se dava esta desodorização social diferenciada, uma questão passou a incitar o imaginário coletivo, o fedor do pobre. É neste sentido que Corbin (1987) afirma que "os locais de amontoamento confuso deixam de monopolizar a análise olfativa dos observadores", quando "uma nova curiosidade convida a desentocar os odores da miséria, a descobrir o fedor do pobre e de sua toca".

No contexto descrito do século XIX, a terapêutica política pregada pela medicina social deve ser traduzida, também, como uma ação sobre o cheiro da pobreza, da imundície dos pobres. A qualificação do cheiro do rico e do cheiro do pobre foi um dos fatores que permitiram a introdução das questões sociais no debate sobre saúde e doença. No entender de Rudolph Virchow, o mais proeminente dos médicos sociais, as epidemias se diferenciavam em naturais, que atribuía a fatores como o clima e as estações do ano, e artificiais, que acreditava provocadas por "defeitos produzidos pela organização social e política” (Rosen, 1980). Assim, para Virchow, a terapêutica "ontológica" dos clínicos iniciais, voltada para a especificidade dos sinais e sintomas das doenças, não se adequava aos miasmas. Os agentes morbíficos dos anticontagionistas eram reconhecidos na distinção entre ricos e pobres, sendo os mais perniciosos aqueles expelidos no espaço olfativo, onde se estabeleciam as más condições de vida características dos miseráveis já socialmente classificados do capitalismo industrial.

Segundo Tamayo (1988), na metade do século XIX, pouco antes da afirmação da microbiologia, as teorias do contágio atingiram seu maior declínio. Foi quando o anticontagio- 
nismo dos revolucionários de 1848 alcançou sua máxima respeitabilidade. Naquele momento, certas questões como o descrédito em relação à especificidade das doenças e a crença na geração espontânea habitavam os espíritos e impediam a aceitação do modelo explicativo do contágio. Além disso, a teoria celular, que revelou o correspondente biológico do átomo da física ao encontrar um novo elemento universal de todos os seres vivos, era jovem demais e o desenvolvimento técnico do microscópio só tomou um impulso mais efetivo na segunda metade do século XIX.

O microscópio ganhou maiores precisão e operacionalidade com as modificações introduzidas pelos conhecimentos de física ótica de Ernst Abbé na indústria de Carl Zeiss, quase 200 anos depois de Anton van Leewenhoek ter observado microorganismos, movimentando-se em uma gota d'água, em 1678. Tamayo (1988) sustenta que este longo desaparecimento do microscópio será esclarecido para qualquer um que tenha a oportunidade de utilizar um destes instrumentos fabricados até o último terço dos anos 1800 e vivenciar a experiência de longas horas de paciência necessárias para o simples enquadramento e ajuste da imagem. O aperfeiçoamento do microscópio, em combinação com o desenvolvimento de técnicas laboratoriais para isolamento e preparação de material para exame, possibilitaram a comprovação fotográfica da teoria microbiana, com os trabalhos de Koch.

Deve ser observado que desde a abertura dos corpos, no nascimento da clínica, foi reforçada a noção de que a doença se retirava para uma intimidade cada vez mais inacessível do espaço interno do corpo humano (Foucault, 1977). A patologia dos órgãos de Giovanni Battista Morgagni foi anterior ao estudo das membranas de Bichat, tecidos similares que envolviam e atravessavam os órgãos, expressando, como percebe Foucault (1977), “o paradoxo de uma superfície interna (...) um elementar que é, ao mesmo tempo, universal". E esta histologia de Bichat, por sua vez, antecedeu a patologia celular de Virchow. A procura da doença conformou, assim, uma penetração cada vez mais profunda nos corpos, à maneira de um zoom exploratório que prossegue nos dias de hoje, amparado pela tecnologia moderna, em busca do elemento universal da criação, que possibilite a compreensão da vida e o domínio sobre a morte. Na perspectiva da microbiologia de então, o achado de uma causa microscópica da doença, deve ter representado, também, uma conformação à visão de mundo estabelecida pela física Newtoniana na qual tudo se originava de partículas cada vez menores, moléculas e átomos, que se movimentavam e emitiam energia.

As idéias sobre o contágio, presentes nas representações mais remotas, se afirmaram enquanto modelo científico de explicação do processo mórbido com as revelações de Pasteur e Koch. O interesse de Koch pela fotografia e a oportunidade que teve de utilizar os aperfeiçoamentos da microscopia, possibilitaram a comprovação categórica da teoria dos germes e o afastamento do centro do cenário das discussões sociais dos anticontagionistas revolucionários de meados do século XIX. Afinal, não se poderia fotografar um miasma ou uma influência.

Enquanto Koch buscou a etiologia específica com a identificação dos germes e a melhoria das técnicas laboratoriais, Pasteur combateu a geração espontânea e preparou vacinas, expondo ao máximo suas descobertas ao público. A experiência com os "balões de pescoço de cisne", em 1864, em que contestou a geração espontânea, e a vacinação de ovelhas contra o antraz na granja de Poilly-le-Fort, em 1881, foram bastante ilustrativas deste modo de proceder de Pasteur. Usava uma estratégia própria, cujo sucesso Saint-Romain (1991) atribui

"ao modo como passou metodicamente de um domínio ao outro, do estudo da cerveja ao da seda, dos fermentos ao dos micróbios, do leite, do vinho às doenças dos animais e dos homens, envolvendo na trama da sua clientela todas as camadas da sociedade, os industriais e os agricultores, os destiladores de vinho da região $e$ as mães de família".

Assim é que Sournia \& Ruffie (1986) assinalam que o respeitado dicionário Littré, em 1865, definia a infecção como " a ação exercida na economia por miasmas morbíficos", e, na edição de 1908, como "a ação exercida sobre a economia por agentes animados pertencendo 
freqüentemente ao grupo das bactérias e agindo por intermédio dos seus produtos solúveis".

No começo do século XX, a exclusividade microbiológica imperava de tal modo na compreensão de saúde e doença, que Joseph Goldberger, em 1916, chegou a inocular-se com material orgânico de pacientes com pelagra para provar sua etiologia nutricional, não contagiosa. Terris (1987) conta que em Goldberger e seus companheiros pesquisadores foi injetado sangue por via intramuscular e subcutânea, foram-lhes aplicadas secreções nas mucosas do nariz e da nasofaringe e lhes foram administradas placas de descamação e excretas por via oral. Além de alguns distúrbios digestivos, nada ocorreu aos epidemiologistas, sendo sua hipótese confirmada.

Pensando o micróbio, um ser que penetra no corpo e provoca a doença, Canguilhem (1990) anota que

"sem querer atentar contra a majestade dos dogmas de Pasteur, pode-se até dizer que a teoria microbiana das doenças contagiosas deve, certamente, uma parte considerável de seu sucesso ao fato de conter uma representação ontológica do mal”.

Também no âmbito das representações deve ser anotado que, quando formulava as bases da microbiologia, Pasteur admitia que perseguia o

"estudo exato da putrefação [...] por suas possíveis conseqüências para o conhecimento das enfermidades que os antigos chamaram pútridas. Minhas investigações sobre as fermentações me têm conduzido naturalmente a este estudo, sem preocupar-me demasiado com o perigo que representa nem com a repugnância que inspira”. (Martinez-Baéz, 1972)

Passo a passo, Pasteur procurou a fermentação no leite, no vinho e na cerveja, para, então, buscá-la no corpo humano. Ainda que os micróbios fossem os agentes, a doença permanecia sendo a deterioração do corpo, o seu apodrecimento, o que repugnava e cheirava mal.

No dizer de Le Goff (1991b) “da mais remota antigüidade, donde surgem os ainda espantosos documentos da Babilônia, até o bloco operató- rio mais futurista, as atitudes face às doenças em nada se alteraram".

Ainda que reconheça o caráter polêmico da afirmativa do autor, o que vejo é que no domínio das mentalidades, onde as mudanças escorrem vagarosamente, na lentidão da História, mesmo a luta que alimentou o assentamento da microbiologia no século XIX, entre anticontagionistas, defensores dos miasmas enquanto agentes morbíficos, e contagionistas, perde a nitidez de seus contornos ao nível das representações de saúde e doença.

\section{RESUMO}

SEVALHO, G. Uma Abordagem Histórica das Representações Sociais de Saúde e Doença. Cad. Saúde Públ., Rio de Janeiro, 9 (3): 349-363, jul/set, 1993.

$\mathrm{O}$ autor apresenta um ensaio, uma abordagem histórica das representações sociais de saúde e doença nos moldes de uma história cultural, que incorpora alguns aportes da história das mentalidades da escola francesa dos "Annales". Trata-se de uma abordagem que busca a "longue durée", o tempo longo da história onde as permanências são mais evidentes que as mudanças. Em uma introdução é feita uma argumentação sobre a procedência do enfoque escolhido e, num momento seguinte, o texto persegue a caracterização das representações de saúde e doença. Nesta perspectiva resistem vestígios imemoriais, elementos por vezes inconscientes que constituem as mentalidades, conformando uma história vaga, borrada, lenta, impregnada de permanências de origem remota onde se interpenetram a ciência da História, a Antropologia e a Psicologia.

Palavras-Chave: Saúde e Doença; Fatores Sócio-Econômicos; História; Representações Sociais 


\section{REFERÊNCIAS BIBLIOGRÁFICAS}

ALMEIDA-FILHO, N., 1989. Epidemiologia Sem Números: Uma Introdução Crítica à Ciência Epidemiológica. Rio de Janeiro: Campus.

ARIÈS, P., 1990. A história das mentalidades. In: A História Nova (J. Le Goff, org.), pp. 154-176, Rio de Janeiro: Martins Fontes.

BAKHTIN, M., 1993. A Cultura Popular na Idade M édia e no Renascimento - 0 Contexto de François Rabelais. São Paulo: Hucitec.

BIRMAN, J., 1991. Apresentação: interpretação e representação social e saúde coletiva. Physis, 1: 7-22.

BOLTANSKI, L., 1989. As Classes Sociais e o Corpo. Rio de Janeiro: Graal.

BOORSTIN, D., 1989. Os Descobridores. Rio de Janeiro: Civilização Brasileira.

BOTTÉRO, J., 1991. A magia e a medicina reinam na Babilônia. In: As Doenças têm História (J. Le Goff, org.), pp. 11-36, Mem Martins: Terramar.

BRAUDEL, F., 1986. História e Ciências Sociais. Lisboa: Editorial Presença.

BURKE, P., 1992. Abertura, a nova história, seu passado e seu futuro. In: A Escrita da História Novas Perspectivas (P. Burke, org.), pp. 07-37, São Paulo: UNESP.

CANGUILHEM, G., 1990. 0 Normal e o Patológico. Rio de Janeiro: Forense Universitária.

CAPRA, F., 1988. O Ponto de Mutação: a Ciência, a Sociedade e a Cultura Emergente. São Paulo: Cultrix.

CASTIEL, L. D., 1993. O estresse na pesquisa epidemiológica: o desgaste dos modelos de explicação coletiva no processo saúde-doença. Physis, 3: 91-106.

CORBIN, A., 1987. Saberes e Odores: o Olfato e 0 Imaginário Social nos Séculos Dezoito e Dezenove. São Paulo: Companhia das Letras.

DELUMEAU, J., 1989. História do Medo no Ocidente (1300-1800). São Paulo: Companhia das Letras.

FOUCAULT, M., 1977. O Nascimento da Clínica. Rio de Janeiro: Forense Universitária. 1979. M icrofísica do Poder. Rio de Janeiro: Graal.

FOX, R., 1985. Reflections ans opportunities in the sociology of medicine. Journal of Health Social B ehavior, 26: 6-14.

GARCIA, J. C., 1989. 1948: O nascimento da medicina social. In: Pensamento Social em Saúde na América Latina (E. D. Nunes, org.), pp. 156-166, São Paulo: Cortez.

GINZBURG, C., 1991. O Queijo e os Vermes. São Paulo: Companhia das Letras.
GONÇALVES, R. B. M., 1990. Reflexões sobre a articulação entre a investigação epidemiológica e a práticamédica a propósito das doenças crônicas degenerativas. In: Epidemiologia Teoria e Objeto, (D. C. Costa, org.), pp. 39-86, São Paulo: Hucitec-Abrasco.

HERZLICH, C., 1991. A problemática da representação social e sua utilidade no campo da doença. Physis, 1: 23-26.

HERZOG, R., 1991. A concepção de si como sujeito-da-doença. Physis, 1: 143-155.

HOBSBAWM, E. J., 1979. A Era das Revoluções (1789-1848). Rio de Janeiro: Paz e Terra.

HUIZINGA, J., 1978. O Declínio da Idade M édia. São Paulo: Verbo - Editora da Universidade de São Paulo.

HUNT, L., 1992. Apresentação: história, cultura e texto. In: A Nova História Cultural, (L. Hunt, org.), pp. 01-29, São Paulo: Martins Fontes.

LAPLANTINE, F., 1991. Antropologia da Doença. São Paulo: Martins Fontes.

LAQUEUR, T. W., 1992. Corpos, detalhes e narrativa humanitária. In: A Nova História Cultural, (L. Hunt, org.), pp. 239-277, São Paulo: Martins Fontes.

LE GOFF, J., 1988. As mentalidades: uma história ambígua. In: História: Novos Objetos, (J. Le Goff \& P. Mora, orgs.), pp. 68-83, Rio de Janeiro: Livraria Francisco Alves Ed.

, 1989. Os Intel ectuais na Idade M édia.

São Paulo: Brasiliense.

, 1991a. Mercadores e banqueiros na

Idade M édia. São Paulo: Martins Fontes.

, 1991b. Uma história dramática. In: As

Doenças têm História (J. Le Goff, org), pp. 0708, Mem Martins: Terramar.

1991c. As plantas que curam. In: As

Doenças têm História (J. Le Goff, org), pp. 329342, Mem Martins: Terramar.

LE GOFF, J.; LE ROY, E. L. \& DUBY, G., 1989. A Nova História. Lisboa: Edições 70.

LEVI, G., 1992. Sobre a micro-história. In: A Escrita da História - Novas Perspectivas (P. Burke, org.), pp. 133-161, São Paulo: UNESP.

LUZ, M. T., 1988. Natural, Racional, Social: Razão M édica e Racionalidade Científica M oderna. Rio de Janeiro: Campus.

MACHADO, R.; LOUREIRO, A.; LUZ, R. \& MURICY, K., 1978. Danação da Norma. Rio de Janeiro: Graal.

MARTINEZ-BÁEZ, M., 1972. Vida y Obra de Pasteur. México: Fondo de Cultura Econômica.

MINAYO, M. C. S., 1992. O Desafio do Conhecimento - Pesquisa Qualitativa em Saúde. São Paulo/Rio de Janeiro: Hucitec/Abrasco. 
MOSSÉ, C., 1991. As lições de Hipócrates. In: As Doenças têm História (J. Le Goff, org.), pp. 3751, Mem Martins: Terramar.

NUNES, E. D., 1992. As ciências sociais em saúde: reflexões sobre as origens e a construção de um campo de conhecimento. Saúde e Sociedade, 1: 59-84.

PORTER, R., 1985. The patients view-doing medical history from below. Theory and Society, 14: 175-198.

, 1992. História do corpo. In: A Escrita da História - Novas Perspectivas (P. Burke, org.), pp. 291-326, São Paulo: UNESP.

REVEL, J. \&PETER, J. P., 1988. O corpo: o homem doente e sua história. In: História: Novos Objetos, (J. Le Goff \& P. Mora, orgs.), pp. 141159, Rio de Janeiro: Livraria Francisco Alves Ed.

ROSEN, G., 1980. Da Polícia M édica à Medicina Social. Rio de Janeiro: Graal.

SAINT-ROMAIN, A., 1991. Pasteur: as verdadeiras razões de uma glória. In: As Doenças têm História (J. Le Goff, org.), pp. 79-83, Mem Martins: Terramar.

SANTOS-FILHO, L., 1977. História Geral da M edicina Brasileira. São Paulo: Hucitec/USP.
SEVALHO, G., 1992. Permanências Culturais no Uso do M edicamento Alopático Moderno. Tese de Mestrado, Rio de Janeiro: Escola Nacional de Saúde Pública, Fundação Oswaldo Cruz.

SHARPE, J., 1992. A história vista de baixo. In: A Escrita da História - Novas Perspectivas (P. Burke, org.), pp. 39-62, São Paulo: UNESP.

SIGERIST, H., 1987. Hitos en la Historia de la Salud Publica. México: Siglo Veintiuno Editores.

SOURNIA, J. C. \& RUFFIE, J., 1986. As Epidemias na História do Homem. Lisboa: Edições 70.

TAMAYO, R. P., 1988. El Concepto de Enfermedad: su Evolución a Travéz de la Historia. Tomo _ I I II. México: Fondo de Cultura Económica.

TERRIS, M., 1987. La Revolución Epidemiológica y la M edicina Social. México: Siglo Veintiuno.

VIRCHOW, R., 1962. Disease, Life and M an. New York: Collier Books.

VOVELLE, M., 1990. A história e a longa duração. In: A História Nova (J. Le Goff, org.), pp. 63-96, Rio de Janeiro: Martins Fontes.

VOVELLE, M., 1991. Ideologias e M entalidades. São Paulo: Brasiliense. 